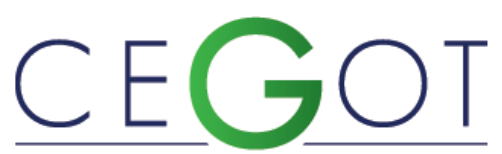

Centro de Estudos de Geografia e Ordenamento do Território
SILVA FARIAS, MÁRCIA REGINA FARIAS DA

Universidade do Estado do Rio Grande do Norte

Programa de Pós-Graduação em Geografia

59611-100, Mossoró, Rio Grande do Norte, Brasil

marciaregina@uern.br

Silva, Ítalo Henrique Monteiro da

Universidade do Estado do Rio Grande do Norte

Departamento de Gestão Ambiental.

Mossoró, Rio Grande do Norte, Brasil

italos211@gmail.com

CARVALHO, RODRIGO GUIMARÃES DE

Universidade do Estado do Rio Grande do Norte

Programa de Pós-Graduação em Geografia

Mossoró, Rio Grande do Norte, Brasil

rodrigocarvalho@uern.br

\title{
ENERGIAS RENOVÁVEIS: O PARQUE EÓLICO DE SÃO CRISTÓVÃO, MUNICÍPIO DE AREIA BRANCA (RN) - BRASIL
}

RENEWABLE ENERGIES: THE SÃO CRISTÓVÃO WIND FARM, MUNICIPALITY OF AREIA BRANCA (RN) - BRAZIL

Referência: SILVA FARIAS, Márcia Regina Farias da; SILVA, Ítalo Henrique Monteiro da; CARVALHO, Rodrigo Guimarães de (2021). ENERGIAS RENOVÁVEIS: O PARQUE EÓLICO DE SÃO CRISTÓVÃO, MUNICÍPIO DE AREIA BRANCA (RN) - BRASIL. Revista de Geografia e Ordenamento do Território (GOT), no 22 (Dezembro). Centro de Estudos de Geografia e Ordenamento do Território, p. 111 - 139, dx.doi.org/10.17127/got/2021.22.005

\section{RESUMO}

O Brasil tem elevado seu potencial de aproveitamento de fontes renováveis de energia, principalmente empreendimentos eólicos que vêm se expandindo no mercado nacional. 0 ganho de espaço na matriz nacional possibilitou a corrida eólica, que, por sua vez, ocasionou problemas socioambientais em decorrência da instalação dos parques eólicos. Esta pesquisa objetivou identificar as mudanças ocorridas na comunidade pesqueira de São Cristóvão, localizada no município de Areia Branca, Rio Grande do Norte (RN), Brasil, a partir da introdução do parque eólico. Adotou-se uma abordagem mista e, para a coleta de dados, fezse uso de visitas in loco associadas à análise de documentos, realização de entrevistas e aplicação de questionários semiestruturados, que foram catalogados e analisados com o auxílio do programa Statistical Package for the Social Sciences (SPSS), versão 20.0. Participaram do estudo 80 (oitenta) pessoas. Como resultado, foi possível identificar que o processo de instalação do parque eólico ocorreu sem uma participação expressiva da comunidade e há ausência de um diálogo aprofundado entre a empresa e a população inserida nas proximidades do parque eólico. Verificou-se que o impacto na economia local após a instalação do empreendimento é inexpressivo, segundo os entrevistados. 
Constataram-se conflitos socioambientais relacionados à posse da terra, e, face a essas questões, a comunidade expressa desconfianças em relação aos parques eólicos na região.

Palavras-chave: Conflitos socioambientais. Comunidades litorâneas. Energia renovável. Empreendimentos eólicos.

\begin{abstract}
Brazil has increased its potential to take advantage of renewable energy sources, mainly wind farms that have been expanding in the national market. The gain of space in the national matrix enabled the wind race, which in turn caused socio-environmental problems as a result of the installation of wind farms. In this direction, this research aimed to identify the changes that occurred in the fishing community of São Cristóvão, located in the municipality of Areia Branca, Rio Grande do Norte (RN), Brazil, from the introduction of the wind farm. A mixed approach was adopted and for data collection, on-site visits associated with photographic record analysis, semi-structured questionnaire applications with open and closed questions were used, cataloged and analyzed with the aid of the Statistical Package for the Social program Sciences (SPSS) version 20.0. 80 (eighty people) participated in the study. As a result, it was possible to identify that the wind farm installation process took place without significant community participation and the absence of an in-depth dialogue between the company and the population located in the vicinity of the wind farm. It was found that the impact on the local economy, after the installation of the enterprise is insignificant, according to the interviewees. It was found that socioenvironmental conflicts related to land tenure and faced with these issues, the community expresses distrust in relation to wind farms in the region.
\end{abstract}

Keywords: Socio-environmental conflicts. Coastal communities. Renewable energy. Wind projects.

\title{
1. Introdução
}

Atualmente, a palavra "energia" tem sido bastante utilizada e discutida em meio às preocupações com o esgotamento dos recursos energéticos. Na busca de soluções renováveis para esses problemas, a "energia renovável" vem ganhando espaço na matriz energética mundial para amenizar os impactos ao meio ambiente.

A energia e o desenvolvimento são fatores que estão intimamente ligados, e por isso devem ser avaliados de forma conjunta. Pode-se afirmar que os países menos desenvolvidos consomem menos energia do que os países desenvolvidos e utilizam, de modo geral, diferentes fontes de energia, gerando diferentes tipos de impactos ambientais.

O desenvolvimento de novas fontes renováveis não se limita ao atendimento a compromissos ou obrigações ambientais, mas também visam ao desenvolvimento de tecnologias no país, 
reduzindo, assim, uma possível dependência de tecnologias de ponta para a produção de energia. Atualmente, é imprescindível que elas estejam inseridas nas políticas energéticas dos países, já que exercem um papel importante para a sustentabilidade do sistema energético.

No Brasil, o Programa de Incentivo às Fontes Alternativas de Energia Elétrica - PROINFA, instituído pela Lei no $10.438 / 2002$, possibilitou o avanço na matriz nacional, incentivando centrais geradoras a implantação de novos projetos eólicos, principalmente no litoral brasileiro (Brasil, 2002). Porém, falhas no PROINFA ocasionaram problemas na implementação de parques eólicos em algumas regiões brasileiras. Esses problemas estavam relacionados às linhas de transmissão, que, por sua vez, não eram implantadas de forma conjunta aos parques, o que impossibilita o escoamento para todo o país da energia.

Essa política voltada para o desenvolvimento territorial foi formulada com o intuito de impulsionar o setor energético renovável, em especial, a geração de energia eólica, considerando que àquela altura o país enfrentava uma série de dificuldades no setor energético e sofria ameaça de apagão ${ }^{1}$. Entretanto na execução do PROINFA, ocorreu uma falta de planejamento que reverberou, sobretudo, no fornecimento e na comercialização da energia produzida. Asssim, a inclusão de novas fontes alternativas adicionadas à matriz energética brasileira provocou uma corrida de investimentos nesse setor.

Assim, a Lei $n^{0}$ 10.080, de 14 de julho de 2016, que regula a exploração da energia eólica e solar no território do Rio Grande do Norte, tem como base a Resolução do CONAMA ${ }^{\circ}$ 462/2014, que normatiza os procedimentos para esse tipo de atividade econômica no Brasil, tomada como referência para os restantes estados brasileiros. Orienta para os procedimentos e os cuidados para os impactos ambientais que poderão causar ao meio ambiente e as comunidades produtoras com esse tipo de atividade econômica por meio da exploração dos ventos para a produção de energia eólica em solo do Rio Grande do Norte (Brasil, 2014).

O litoral da Costa Branca do Estado do Rio Grande do Norte, onde se localiza a área de estudo desta pesquisa, é dotado de potencial eólico, sendo aproveitado por meio de tecnologia de captação do vento, chamada de aerogeradores. A possibilidade da utilização de novas formas

\footnotetext{
${ }^{1}$ O Programa foi lançado durante o racionamento energético adotado no país no fim da década de 1990, com o intuito de aliviar a matriz energética nacional. O PROINFA regulamentou incentivos e estimulou o uso de fontes alternativas e renováveis, além de incorporar à matriz energética nacional a energia eólica, pequenas centrais hidrelétricas e biomassa por meio da cana-de-açúcar. Com isso, correspondeu à necessidade anual, e consequentemente, afastou risco de apagão no país.
} 
de geração de energia passou por debates e tem fundamentação na premissa do "desenvolvimento sustentável", tomando como caminho o aproveitamento dos recursos naturais de forma a minimizar os prejuízos ao ambiente natural.

Esta pesquisa é parte do projeto intitulado: Impactos da Energia Eólica no Litoral do Nordeste: perspectivas para a construção de uma visão integrada da produção de energia "limpa" no Brasil, financiado pelo edital CNPq - Bolsas no País Modalidade Pesquisador Visitante Especial no 09/201, processo 88881.068108/2014-01. Foi desenvolvido pela Universidade Federal do Ceará (UFC) e a Universidade do Texas - EUA, em parceria com a Universidade do Estado do Rio Grande do Norte (UERN), por meio do Programa de Pós-Graduação em Geografia (PPGEO).

O projeto objetivou analisar, a partir de uma visão dos sistemas socioecológicos, as perspectivas ambientais e sociais da implantação e do funcionamento de três parques eólicos instalados em setores do litoral oeste do Ceará, região de maior concentração de empreendimentos de energia eólica do estado, produzindo inter-relações e analogias com parques eólicos implementados no estado do Texas, considerado o líder de geração de energia eólica nos Estados Unidos (Meireles et al., 2014).

O referido projeto abriu espaço para o desenvolvimento de outros projetos, a exemplo do Projeto: Políticas Territoriais, Governança Ambiental e Energias Renováveis: a Implementação do Parque Eólico na Comunidade de São Cristóvão, Areia Branca (RN). Edital no 003/2016DPI/PROPEG/UERN (PIBIC/CNPq 2017/2018), cujos resultados são abordados neste artigo. A partir do estudo de Meireles et al. (2014), buscou-se ampliar essa análise para o estado do Rio Grande do Norte, no qual vem sendo desenvolvidas pesquisas em nível de pós-graduação no PPGEO, voltadas para o entendimento dos impactos socioambientais das instalações dos parques eólicos no Rio Grande do Norte (Silva, 2017).

Nessa direção, o objetivo desta pesquisa foi identificar as mudanças no modo de vida dos moradores de São Cristóvão, no município de Areia Branca, estado do Rio Grande do Norte (RN), Brasil, após a instalação do parque eólico na comunidade. 


\section{O incentivo à produção de energia limpa}

A adoção de fontes renováveis no mundo teve início diante da crise do petróleo na década de 1970. A partir desse período, foram adotadas medidas com o propósito de assegurar o fornecimento de energia elétrica (Morelli, 2012).

Nas últimas décadas, a segurança sobre a oferta de energia está intrinsecamente associada aos problemas de esgotamento de reservas de petróleo e à elevação dos preços de mercado dos combustíveis fósseis em consequência de problemas políticos e sociais nas principais regiões produtoras. Com toda essa demanda motivada pelo crescimento populacional e econômico, foi acrescida a matriz energética mundial, fontes renováveis, sendo implementada aos poucos por países do Norte e do Sul global.

Após inúmeros debates sobre o direito ao desenvolvimento, era apresentado pela Organização das Nações Unidas (ONU) em 1986 como um direito inalienável, ou seja, um direito essencial e indispensável à sociedade. Com isso, a responsabilidade sobre o direito ao desenvolvimento passou a ser um item constitucional que, por meio de requisitos legais, caberia ao Estado promover e efetivar.

A Declaração sobre o Direito ao Desenvolvimento, aprovada pela Assembleia Geral das Nações Unidas em 1986, é o símbolo de uma nova maneira de versar sobre a concretização dos ideais das Nações Unidas, pois ela proclama que, a pessoa humana é o sujeito central do desenvolvimento e deve ser o participante ativo e o beneficiário do direito ao desenvolvimento.

A Declaração Universal sobre o Direito ao Desenvolvimento apresentava a inter-relação entre economia e sociedade. Procurava-se principalmente criar soluções na busca da estabilidade social e o bem-estar da população, buscando a igualdade de direitos e do livre arbítrio dos povos. O Direito ao Desenvolvimento passou a ser universal e essencial como qualquer outro, e todos os direitos humanos (fundamentais, civis, políticos, econômicos, culturais etc.) são dependências bilaterais (Xavier; Alves; Guimarães, 2013).

A vertente sobre energia se origina de um direito fundamental e civil, uma vez que toda a sociedade necessita desse recurso como utilidade pública, e essa inexistência sobre o abastecimento elétrico provoca na humanidade retrocessos. Esses, por sua vez, geram 
problemas principalmente sobre o desenvolvimento da sociedade. Entretanto, a busca pelo desenvolvimento por meio das necessidades humanas secundarizou outro problema, a respeito da disponibilidade dos recursos naturais para a obtenção de energia. As fontes de energia tradicionais, de origem fóssil, provocaram a busca irracional desse tipo de recurso, causando um enorme impacto socioambiental.

Dentre os impactos provocados diante da produção e consumo dos combustíveis fósseis, as mudanças climáticas provenientes das emissões dos gases com efeito de estufa acarretaram uma série de debates a respeito dos níveis de emissões de poluentes atmosféricos e a crise ambiental que se instalava. Diante disso, a necessidade por fontes alternativas de energia colocou o mundo em uma espécie de revolução energética (Xavier; Alves; Guimarães, 2013). Nessa perspectiva, o conceito de desenvolvimento sustentável aplicado ao modelo mundial, visava a minimizar os impactos provocados pelo consumo por combustíveis fósseis. Adaptando modelos de captação energética de origem renovável, tais como: hidráulica, solar, eólica ou biomassa. Essas fontes têm o mesmo valor energético, atualmente inclusas no modelo de políticas energéticas mundiais, e exercem um sistema sustentável, pelo fato de apresentarem baixos danos ao meio ambiente.

Em se tratando do Brasil, a preocupação sobre o ambiente natural veio logo após a Conferência de Estocolmo, em 1972, motivando, posteriortente, a criação da Lei no 6.938/81, sobre a salvaguarda do meio ambiente e a adoção de ferramentas técnico-jurídiconormativas (Brasil, 1981). Adiante, a Lei no 7.783/89, por sua vez, estabeleceu a energia elétrica como um serviço essencial para o país, sendo assegurado o direito de uso. A lei referida dispõe sobre o direito de greve que assegura o uso e as atividades essenciais para a sociedade brasileira (Xavier; Alves; Guimarães, 2013).

Nos anos conseguintes, a agenda ambiental possibilitou diversos encontros, a Rio-92, por exemplo, proporcionou o debate voltado à redução de emissões de poluentes, os países signatários assinaram o então chamado Protocolo de Quioto, um fato inédito que marcaria historicamente uma nova era sobre o desenvolvimento sustentável e a responsabilidade compartilhada. Contudo, a Lei no 9.478, de 6 de agosto de 1997, fundamentava o petróleo como principal fonte de abastecimento da matriz energética brasileira (Brasil, 1997). 
Cavalcante (2013) ressalta que a reformulação e criação de leis trouxe ao país soluções objetivas a partir da criação de metas. Para isso, cita a Lei no 9.478/97, que elencava o planejamento setorial de várias regiões, buscando incentivos a fontes de energia renováveis. No entanto, a crise de 2001, marcada por vários apagões, motivou o Governo Federal à criação de novas medidas, no intuito de solucionar ou minimizar o problema.

Diante disso, a universalização do setor energético foi criada pelo Decreto no 4.541/2002, que culminou com o reflexo de uma nova consonância do setor energético nacional. $\mathrm{O}$ uso de Resoluções e Decretos trouxe também o incentivo de geração de energia elétrica ou pequenas centrais geradoras a partir de fontes renováveis. A Lei № 10.438 instituiu o Programa de Incentivo às Fontes Alternativas de Energia Elétrica -PROINFA, regulamentada pelo Decreto no 5.025/2004 (Veiga; Oliveira; Pereira, 2012).

Com o fracasso do Programa Emergencial de Energia Eólica - PROEOLICA, um plano emergencial que criava $1.050 \mathrm{Mw}$, o PROINFA impulsionou, significativamente, desde sua criação, em 2002, as fontes de energia renováveis no Brasil, especialmente a perspectiva eólica, expandindo a geração de energia eólica nacionalmente. Com a criação do PROINFA, novos nortes foram tomados, a criação de novos planos e projetos tentavam planejar o recurso energético nacional, de modo a garantir uma expansão do setor elétrico sistemático (Nascimento; Mendonça; Cunha, 2012).

Desde os anos 2000, o tema energia limpa vem sendo debatido com frequência no Brasil e no mundo. A ONU, nos anos 2000, promoveu uma reunião denominada de Cúpula do Milênio, que envolveu representantes de 189 países. Os debates deste evento foram fundamentados na busca por soluções para inúmeros problemas sociais, econômicos, políticos e ambientais, e teve como resultado a elaboração do documento conhecido como Declaração do Milênio, com objetivos e metas a serem implementados até 2015 (ONU, 2018).

Nessa mesma direção em 2015, a ONU lançou a Agenda 2030, instituindo 17 objetivos para o desenvolvimento sustentavel (ODS), cujo Objetivo 7 trata de "Energia Acessível e Limpa", com o intuito de assegurar o acesso confiável, sustentável, moderno e a preço acessível à energia para toda a sociedade (ONU, 2021). Esse objetivo visa a assegurar o acesso universal para toda a sociedade; o aumento da participação de energias renováveis na matriz global; a melhoria na eficiência energética; a cooperação internacional de pesquisa tecnológica na área 
de energias renováveis e a expansão da infraestrutura e modernização tecnológica para o fornecimento do serviço energético moderno e sustentável. O ODS 7 ressalta na sua meta 7.2 até 2030 "aumentar substancialmente a participação de energias renováveis na matriz energética global" (ONU, 2021, on-line), evidenciando a importância do fortalecimento de uma matriz energética limpa no âmbito mundial, com responsabilidade socio-ambiental.

Em 2015, o Brasil assinou o compromisso internacional na Conferência das Partes (COP 21) de aumentar para $33 \%$ o uso de fontes renováveis no país. No mesmo período, o Estado do Rio Grande do Norte ganhou destaque nacionalmente como liderança em produção de energia eólica na matriz energética brasileira (Brasil, 2015).

De acordo com o Atlas de Energia Elétrica do Brasil (2002), a primeira turbina eólica instalada no país data de 1992, no Arquipélago Fernando de Noronha, no estado de Pernambuco (PE), coordenada pela Universidade Federal de Pernambuco (UFPE) e financiada pelo Instituto de Pesquisa Dinamarquês Folkecenter, em parceria com a Companhia Energética de Pernambuco (CELPE) (Brasil, 2002).

No Brasil, mais de $71.000 \mathrm{~km}^{2}$ do território nacional possuem velocidades de vento superiores a $7 \mathrm{~m} / \mathrm{s}$ ao nível de $50 \mathrm{~m}$, o que permite um potencial eólico da ordem de 272 Terawatthora/ano (TWh/a) de energia elétrica. A maior parte desse potencial está na costa dos estados da Região Nordeste, como consequência dos ventos alísios (Brasil, 2002).

De acordo com a Agência Nacional de Energia Elétrica (ANEEL) (2017), o Rio Grande do Norte é o estado brasileiro que mais produz energia, usando a força dos ventos, com um total de 135 parques em funcionamento. O litoral Costa Branca no RN vem se destacando nesse setor, localizado na direção setentrional do Rio Grande do Norte, região que apresenta um percentual energético eólico outorgado de aproximadamente 758.690 kilowatt (kW), assim disposto na Tabela 1.

O município de Areia Branca, por exemplo, dispõe de um total de 160.400 kW de capacidade energética, distribuída em 64 aerogeradores, 10 deles localizados na comunidade de São Cristóvão. Esses aerogeradores fazem parte do empreendimento Mel 2 Energia Renovável S/A. 
Tabela 1 - Distribuição da capacidade energética eólica no litoral da Costa Branca, Rio Grande do Norte (2020).

\begin{tabular}{l|c}
\hline \multicolumn{1}{c|}{ Municípios } & Capacidade Energética (kW) \\
\hline Areia Branca & 160.400 \\
\hline Caiçara & 45.000 \\
\hline Galinhos & 118.570 \\
\hline Guamaré & 284.450 \\
\hline Macau & 70.270 \\
\hline São Bento do Norte & 80.000 \\
\hline
\end{tabular}

Fonte: Agência Nacional de Energia Elétrica (ANEEL), 2017.

\section{Metodologia}

A pesquisa foi realizada na comunidade de São Cristóvão, localizada no município de Areia Branca, Estado do Rio Grande do Norte, na região Nordeste do Brasil (Medeiros et al., 2011), nas coordenadas de $4^{\circ} 55^{\prime} 30^{\prime \prime}$ e $4^{\circ} 57^{\prime} 0^{\prime \prime}$ de latitude Sul e $36^{\circ} 56^{\prime} 0^{\prime \prime}$ e $36{ }^{\circ} 58^{\prime} 30^{\prime \prime}$ de longitude Oeste, conforme Figura 1. A população residente em Areia Branca, no ano de 2019, foi estimada em 27. 967 habitantes e a de São Cristóvão é de 663 habitantes (IBGE, 2021).

A escolha da comunidade de São Cristóvão deu-se pela implantação do parque eólico na comunidade. A partir dessa iniciativa de produção energética, problemas de ordem socioambiental passaram a ser visíveis na comunidade, interferindo na dinâmica local e ocasionando mudanças no modo de vida dos moradores.

A pesquisa foi desenvolvida por meio da proposta de Meireles et al. (2014) e adotou uma abordagem mista. A pesquisa de métodos mistos combina elementos das abordagens qualitativa e quantitativa, ao considerar que ambas se complementam. 


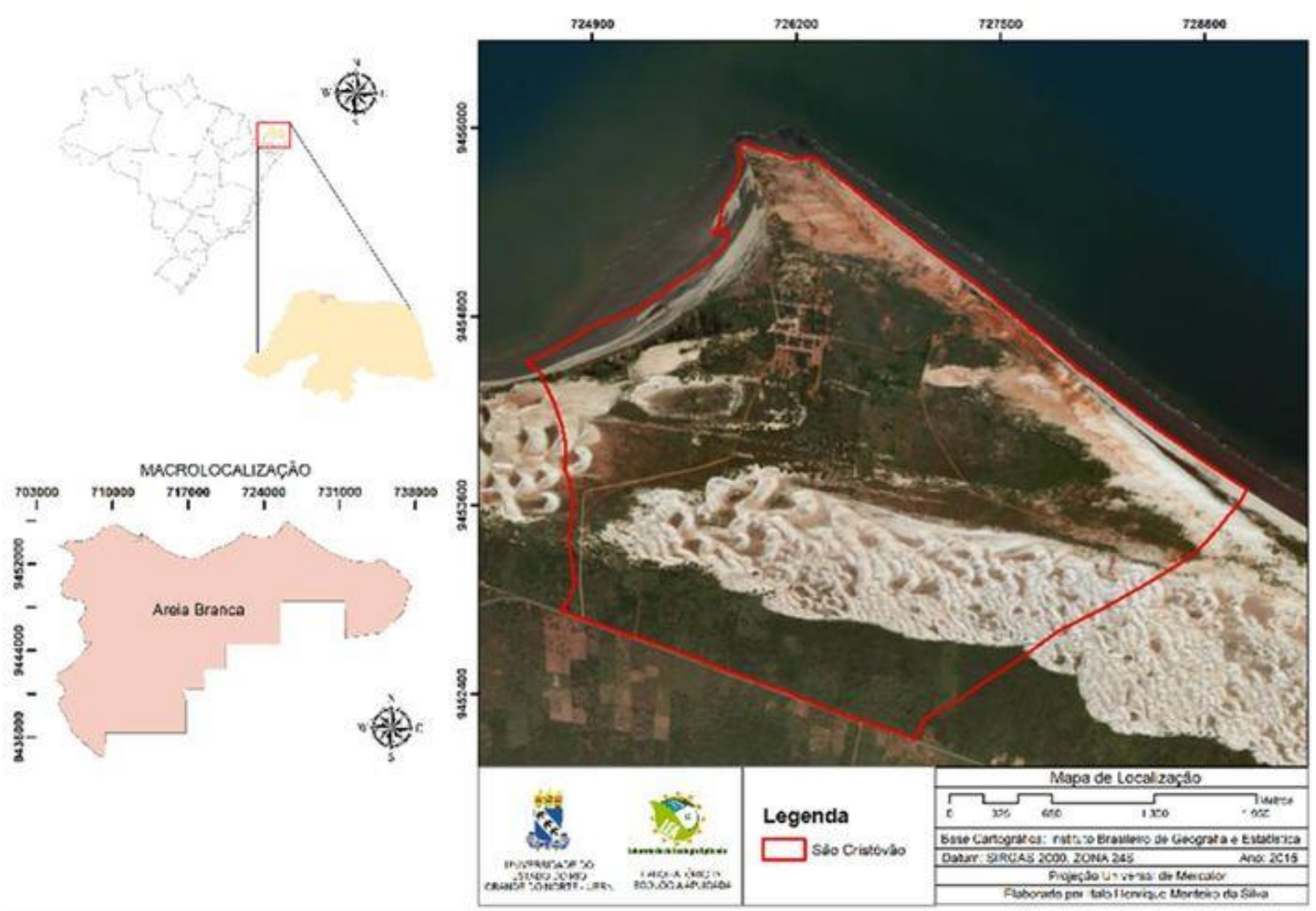

Figura 1 - Mapa de localização da comunidade de São Cristóvão, Areia Branca (RN).

Fonte: Instituto Brasileiro de Geografia e Estatística (IBGE, 2015).

Foi utilizada como técnicas de coleta de dados a análise documental e para o trabalho de campo observações in loco, questionário e entrevista. Assim, o procedimento metodológico foi realizado em quatro momentos distintos, a saber:

Inicialmente, foi realizado o levantamento e a seleção dos documentos. Essa pesquisa se deu por meio de consultas de escrituras públicas, no Cartório do Município de Areia Branca, com a finalidade de entender conflitos relacionados ao uso e ocupação das terras onde se encontra instalado o parque eólico de São Cristóvão. Foram também consultadas atas de reuniões da Associação Comunitária de São Cristóvão e dados secundários disponíveis no site da Agência Nacional de Energia Elétrica (ANEEL), do Ministério das Minas e Energia (MME), entre outros. Nessa etapa, foi também realizado o levantamento da legislação vigente, voltado ao incentivo e à orientação da instalação de parques eólicos no Brasil. A finalidade dessa busca foi reunir informações para compor o quadro de proposições de políticas territoriais de incentivo à atividade eólica. Para Fonseca (2002), a pesquisa documental aprofunda os conhecimentos acerca de um determinado objeto de estudo e propicia ampliar as fontes de dados. Assim, 
buscou-se nesta etapa identificar fontes para aprofundar os conhecimentos sobre a instalação do parque eólico na comunidade de São Cristóvão.

No segundo momento da pesquisa, foram realizadas visitas à comunidade $\mathrm{e} o$ acompanhamento de reuniões da Associação Comunitária. Nesses momentos, foram realizadas observações in loco de elementos naturais e artificiais da paisagem, assim como foram observadas as ações cotidianas dos moradores locais e a dinâmica comunitária, que são os pilares da construção do modo de vida local. As anotações foram realizadas em um diário de campo e analisadas posteriormente.

No terceiro momento, foram aplicados questionários semiestruturados com perguntas abertas e fechadas, junto a 80 (oitenta) moradores locais. Os critérios utilizados para a escolha da amostra foram: ser morador do entorno do parque eólico ou ser comerciante local e ter mais de 20 anos de idade. Assim, foram aplicados 50 (cinquenta) questionários com os moradores do entorno do parque eólico, no intuito de compreender as mudanças mais significativas no modo de vida da população após a implantação do parque eólico e 30 (trinta) questionários com comerciantes locais, procurando entender se ocorreram mudanças significativas na economia local após a instalação do parque eólico.

No quarto momento, foram realizadas 05 (cinco) entrevistas estruturadas com 01 (um) representante do poder público municipal, 01 (um) do poder estadual e 01 (um) do federal. Foi também realizada entrevista com 01 (um) representante do parque eólico e com 01 (um) representante de ONG, com o objetivo de buscar entender as diferentes visões acerca da instalação do parque eólico na comunidade de São Cristóvão.

Na realização da pesquisa, foi solicitada a assinatura do Termo de Adesão (TA) junto à Associação Comunitária, bem como a assinatura do Termo de Compromisso Livre e Esclarecido (TCLE) aos participantes que responderam aos questionários e a assinatura do Termo de Autorização de Gravação Audiovisual e Uso de Imagem (TAGAUI) às pessoas que cederam as entrevistas.

Os dados coletados foram catalogados e analisados com auxílio do programa Statistical Package for the Social Sciences (SPSS), versão 20.0, visando a estabelecer relações entre variáveis e entender aspectos sociaambientais decorrentes da instalação do parque eólico na comunidade. 


\section{Resultados e discussão}

A instalação do empreendimento eólico na comunidade de São Cristóvão teve seu início em 1 de fevereiro de 2011. Na ocasião, a chegada dos investimentos eólicos na região garantiam diversidade de empregos e davam à população do entorno à obra prioridade de contratação. Segundo dados da empresa Força Eólica do Brasil, administradora da obra inicial, garantiu a oferta de 320 postos de trabalho atribuídos por todo o município de Areia Branca. Tavares (2016) menciona que o desenvolvimento local está associado diretamente à promoção de emprego e renda na localidade, a partir da demanda das empresas por mão de obra.

Apesar da disponibilidade inicial de emprego, a população da comunidade demonstrou insatisfação com o parque eólico, não sendo favorável à instalação. Esse resultado está atrelado com promessas de melhores condições de infraestrutura local que não foram realizadas durante a fase de implantação e operação do empreendimento eólico e aos problemas socioambientais associados ao parque, sendo perturbações trazidas ao meio biótico, físico e socioeconômico. Essa insatisfação pode ser observada na Figura 2.

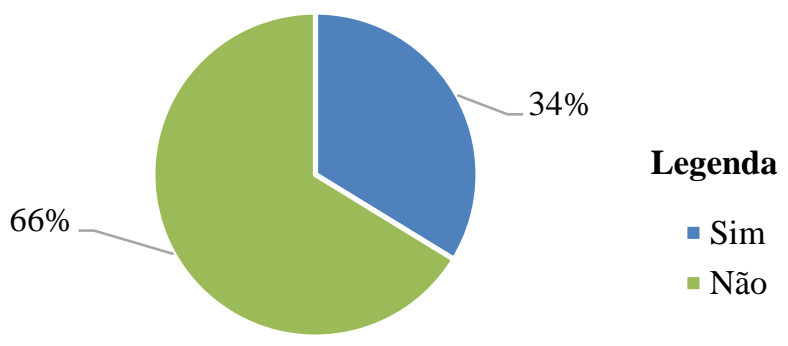

Figura 2 - Gráfico satisfação da população em relação à instalação do parque eólico (\%), 2017.

Fonte: Pesquisa de Campo, 2017.

A Figura 2 apresenta 34\% dos moradores que participaram desta pesquisa estão satisfeitos com a instalação do parque eólico na comunidade e $66 \%$ das pessoas ouvidas estão insatisfeitas com o empreendimento eólico em São Cristóvão. A infatisfação dos moradores encontra-se estreitamente relacionada à forma como ocorreu a implantação do parque eólico. Os moradores alegam que as medidas compensatórias que foram assumidas pelas empresas e a reunião de apresentação do projeto aos comunitários não foram cumpridas e 
este fato causou insatisfação nos moradores locais, não há registro formal do compromisso da empresa em relação ao cumprimento das medidas mitigatorias.

De acordo com os entrevistados, o empreendimento eólico antes da instalação prometeu realizar medidas mitigatórias, como a construção de estrada para melhorar o acesso à comunidade, investimentos em projetos sociais, diminuição da tarifa da conta de energia das residências e ações de infraestrutura na comunidade. Como essas medidas não foram cumpridas, tem sido as principais reinvindicações dos moradores, em relação ao compromisso não assumido pela empresa. Pesquisa realizada por Moreira et al. (2013) menciona que há um alto nível de insatisfação por parte dos moradores de comunidade que passaram pelo processo de instalação de parque eólico. Observa-se que há sempre relatos de ilusões alimentadas nos moradores, por falsas promessas que não se cumprem com a instalação dos parques eólicos.

\subsection{Impactos socioambientais decorrentes da instalação do parque eólico em São Cristóvão}

Impacto ambiental é definido, conforme o Conselho Nacional do Meio Ambiente - CONAMA, por meio da Resolução 01/96, como qualquer alteração das propriedades físicas, químicas e biológicas do meio ambiente causada por qualquer forma ou matéria ou energia resultante das atividades humanas que direta ou indiretamente, afetam: I - a saúde, a segurança e o bem estar da população; II - as atividades sociais e econômicas; III - a biota; IV - as condições estéticas e sanitárias do meio ambiente; V-a qualidade dos recursos ambientais (Brasil, 1996, art. 1).

Em relação aos impactos socioambientais registrados na área de estudo, foi possível constatar, a partir dos dados revelados pelos questionários e das observações in loco, que eles ocorreram em dois momentos distintos, a saber: o período de instalação do parque eólico e o período de operação da unidade geradora, conforme é apresentado no Quadro 1. 
Quadro 1 - Impactos socioambientais decorrentes da atividade eólica em São Cristóvão, 2018.

\begin{tabular}{|c|c|c|c|}
\hline № & Impactos & Causa/Efeito & Fase \\
\hline 1 & $\begin{array}{l}\text { Degradação da } \\
\text { área afetada }\end{array}$ & $\begin{array}{l}\text { Desmatamento, topografia e terraplenagem, } \\
\text { provocando perda de habitat, soterramento de } \\
\text { vegetação, impermeabilização e compactação do solo, } \\
\text { alteração da paisagem, interferência em área de } \\
\text { preservação ambiental. }\end{array}$ & Instalação \\
\hline 2 & $\begin{array}{l}\text { Degradação do } \\
\text { solo e subsolos }\end{array}$ & $\begin{array}{l}\text { Obras estruturantes de engenharia civil (fundações, } \\
\text { escavações, terraplanagem e construções de acessos), } \\
\text { erosão nas áreas desmatadas, mau gerenciamento de } \\
\text { entulhos. Contaminação de resíduos provenientes dos } \\
\text { maquinários pesados. }\end{array}$ & Instalação \\
\hline 3 & $\begin{array}{l}\text { Degradação do } \\
\text { ambiente dunar }\end{array}$ & $\begin{array}{l}\text { Interferência no processo de movimentação das } \\
\text { dunas, aceleração da erosão de dunas e bloqueios de } \\
\text { acesso pela grande movimentação de areia quartzosa. }\end{array}$ & Instalação \\
\hline 4 & Poluição hídrica & $\begin{array}{l}\text { Abertura de canais no subsolo, poluição por meio dos } \\
\text { resíduos veiculares. Desnudamento e poluição do } \\
\text { lençol freático, má gerência do recurso hídrico. }\end{array}$ & Instalação \\
\hline 5 & $\begin{array}{l}\text { Poluição } \\
\text { atmosférica }\end{array}$ & $\begin{array}{l}\text { Fumaça proveniente do processo de queima dos } \\
\text { combustíveis fósseis, poeira e fuligem provocadas por } \\
\text { caminhões. Movimentação de materiais particulados } \\
\text { durante a movimentação constante de veículos no } \\
\text { pátio de obras. }\end{array}$ & Instalação \\
\hline 6 & $\begin{array}{l}\text { Supressão da } \\
\text { vegetação }\end{array}$ & $\begin{array}{l}\text { Supressão da vegetação nativa, extração de terra e } \\
\text { compactação do terreno, promovendo alteração da } \\
\text { paisagem, perda de habitat natural dos animais } \\
\text { nativos e interferência em área de preservação } \\
\text { ambiental. }\end{array}$ & Instalação \\
\hline 7 & Fauna & $\begin{array}{l}\text { Risco de colisão de aves e morcegos com os } \\
\text { aerogeradores, colisão com as linhas de transmissão } \\
\text { energética, perturbação da avifauna local (reprodução } \\
\text { e migração), alteração dos padrões de movimentação } \\
\text { e alimentação das espécies de aves. }\end{array}$ & $\begin{array}{c}\text { Instalação e } \\
\text { operação }\end{array}$ \\
\hline 8 & Poluição Sonora & $\begin{array}{l}\text { Depende muito da geomorfologia do ambiente, a } \\
\text { velocidade e direção do vento. Durante o processo de } \\
\text { instalação, o barulho provocado pelo maquinário } \\
\text { pesado era constante, o que provocava estresse nos } \\
\text { moradores da comunidade. Relacionado aos } \\
\text { aerogeradores, o ruído no período de operação causa } \\
\text { dores de cabeça e pressão nos ouvidos. }\end{array}$ & $\begin{array}{c}\text { Instalação e } \\
\text { operação }\end{array}$ \\
\hline 9 & Impacto visual & $\begin{array}{l}\text { A instalação e operação do parque através de suas } \\
\text { estruturas (aerogeradores e subestações coletoras) } \\
\text { provocou alteração da paisagem local. A disposição de } \\
\text { matérias do processo de construção, como os } \\
\text { entulhos foi despejada de forma irregular dentro da } \\
\text { comunidade. }\end{array}$ & $\begin{array}{c}\text { Instalação e } \\
\text { operação }\end{array}$ \\
\hline 10 & $\begin{array}{l}\text { Interferências } \\
\text { locais }\end{array}$ & $\begin{array}{l}\text { Aumento do fluxo veicular, aumento temporário da } \\
\text { densidade demográfica local, geração de empregos } \\
\text { provisórios, especulação imobiliária e conflitos por } \\
\text { terras e pouca dinamização das atividades } \\
\text { econômicas. }\end{array}$ & $\begin{array}{l}\text { Instalação e } \\
\text { operação }\end{array}$ \\
\hline
\end{tabular}

Fonte: Pesquisa de Campo, 2017/2018. 
Quando questionados sobre o principal problema durante o processo de instalação, $66 \%$ dos moradores afirmaram ser a destruição da vegetação nativa; 33\% responderam que era a retirada da vegetação e a degradação das dunas e 1\% não respondeu.

De acordo com o representante do poder público estadual, "o período de instalação do parque é muito impactante uma vez que a população é afetada com o movimento de carros e caminhões que transportam as peças dos aerogeradores, materiais de construção, aumenta também fluxo de pessoas na comunidade" (informação verbal) ${ }^{2}$.

Apesar de a produção de energia eólica ser considerada limpa, ela também apresenta impactos na sua produção. Assim, quanto aos principais impactos ambientais decorrentes de empreendimentos eólicos, Meireles (2011), Barbosa Filho (2013), Gê, Carvalho e Silva (2019) e Cunha, Silva e Carvalho (2019) destacam que podem ser divididos em impactos ao meio biótico (fauna e flora), meio físico (degradação da área afetada e alteração do nível hidrostático do lençol freático) e socioeconômico (emissão de ruído, impacto visual, corona visual ou ofuscamento, interferência eletromagnética, efeito estroboscópico e interferências locais). Em relação ao meio biótico, é possível destacar que os empreendimentos eólicos, como todo grande empreendimento, geram impactos significativos ao ambiente, que, por sua vez, geram estresse e danos ao ambiente natural, o risco de colisão de aves sobre estruturas de transmissão e produção (aerogeradores) energética, além de promover na fauna a alteração do ciclo reprodutor, perturbação e migração de espécie, perda do habitat natural e reprodutor, bem como mudança no ciclo de rota de aves.

Constatou-se que o parque eólico de São Cristóvão localiza-se dentro de uma Área de Proteção Ambiental (APA), ou seja, em ambiente de Dunas, como pode ser observado na Figura 3.

\footnotetext{
${ }^{2}$ Entrevista concedida por G.S., representante do poder público, aos pesquisadores.
} 


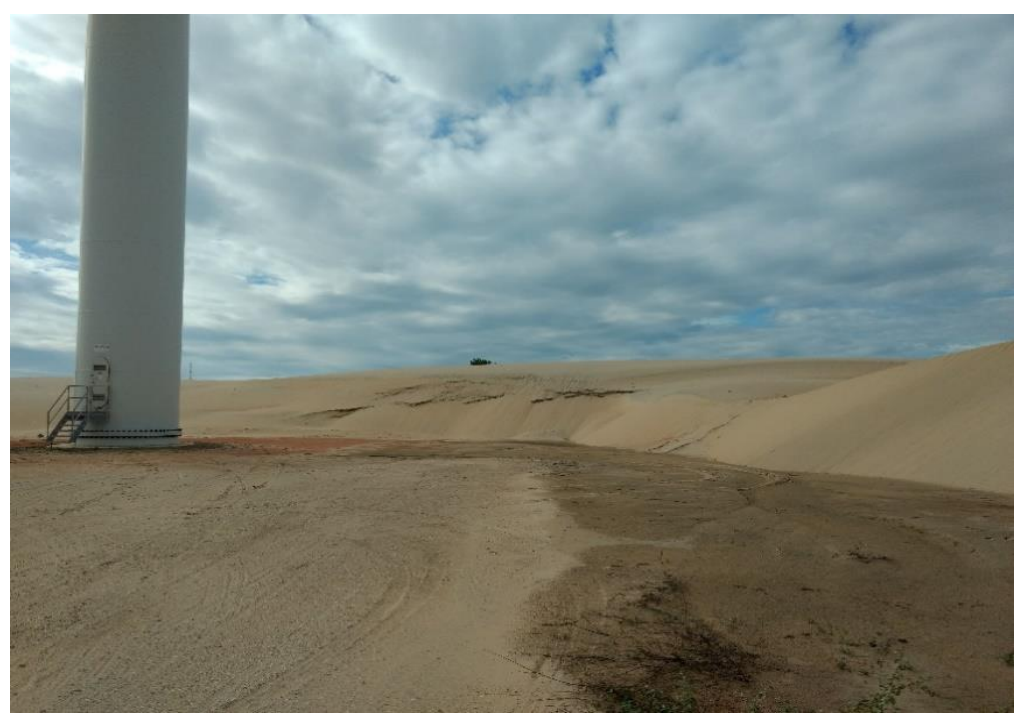

Figura 3 - Localização da base da torre na área de dunas, São Cristóvão, Areia Branca (RN), 2018.

Fonte: Arquivo do Projeto, 2018.

Conforme a Lei no 9.985/2000, que rege o Sistema Nacional de Conservação da Natureza (SNUC), as APA's são Unidades de Conservação (UC) destinadas à proteção e conservação da qualidade ambiental e dos ecossistemas nela inseridos, com vistas à melhoria da qualidade de vida da população local. Entretanto, o parque está inserido dentro da APA "Dunas do Rosado", alterando ambiente natural, como pode ser observado na Figura 4.
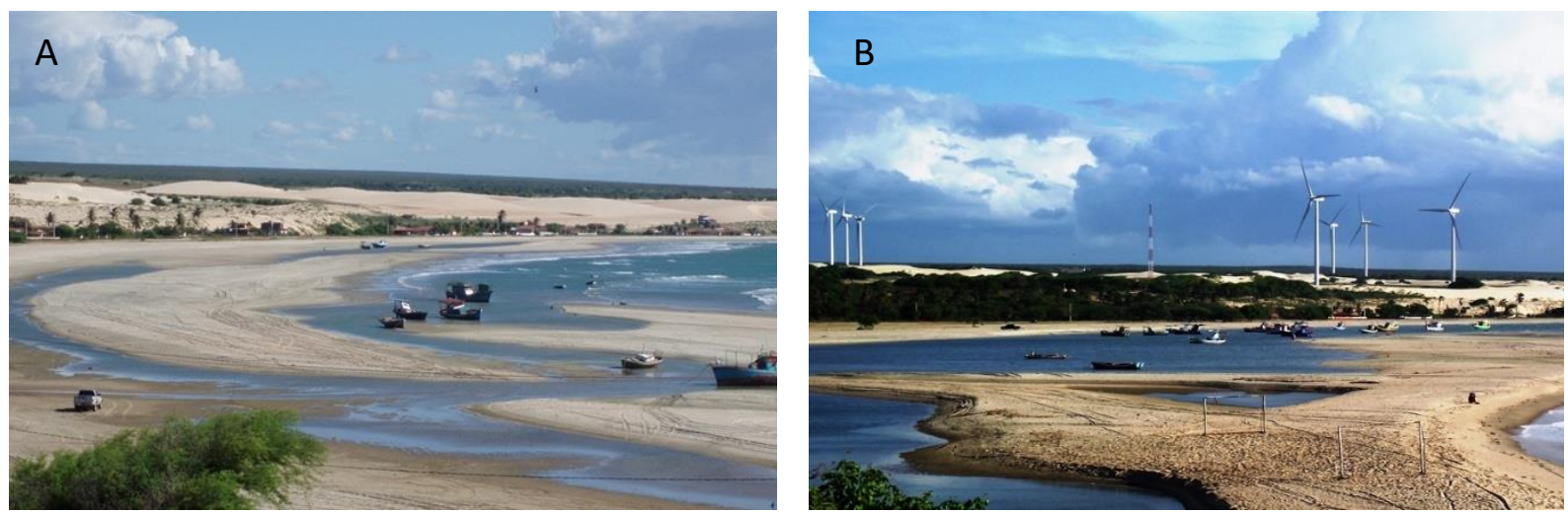

Figura 4 - Alteração do ambiente natural, 4. A (antes) e 4. B (depois) da implantação do parque em São Cristóvão, Areia Branca (RN), 2009 e 2016.

Fonte: Associação Comunitária de São Cristóvão, 2009 e 2016. 
No município de Areia Branca, onde se localiza São Cristóvão, existem áreas que podem ser denominadas de áreas institucionais e especiais. Uma delas é a Área de Proteção Ambiental Dunas do Rosado, que abrange cerca de 16.593,76 hectares, inserida ao longo de dois municípios, sendo eles Areia Branca/RN e Porto do Mangue/RN. A formação geológica é resultado da acumulação de areia advinda dos movimentos dos ventos. Tem esse nome por ter a característica de dunas, com um tom rosado, que se encontra com as areias brancas, e é considerada um monumento geológico do Rio Grande do Norte (Silva, 2018).

A APA Dunas do Rosado é regulamentada pelo Decreto no 27.695, de 21 de fevereiro de 2018, na jurisprudência do Governo do Estado do Rio Grande do Norte, e tem o objetivo de proteger a diversidade biológica, disciplinar o processo de ocupação e assegurar a sustentabilidade do uso dos recursos naturais. Esse importante patrimônio geológico possui interesse turístico e, se planejado de forma adequada, pode ser utilizada e atrair visitantes, mantendo as feições originais desse ecossistema dunar, conforme demonstra a Figura 5.

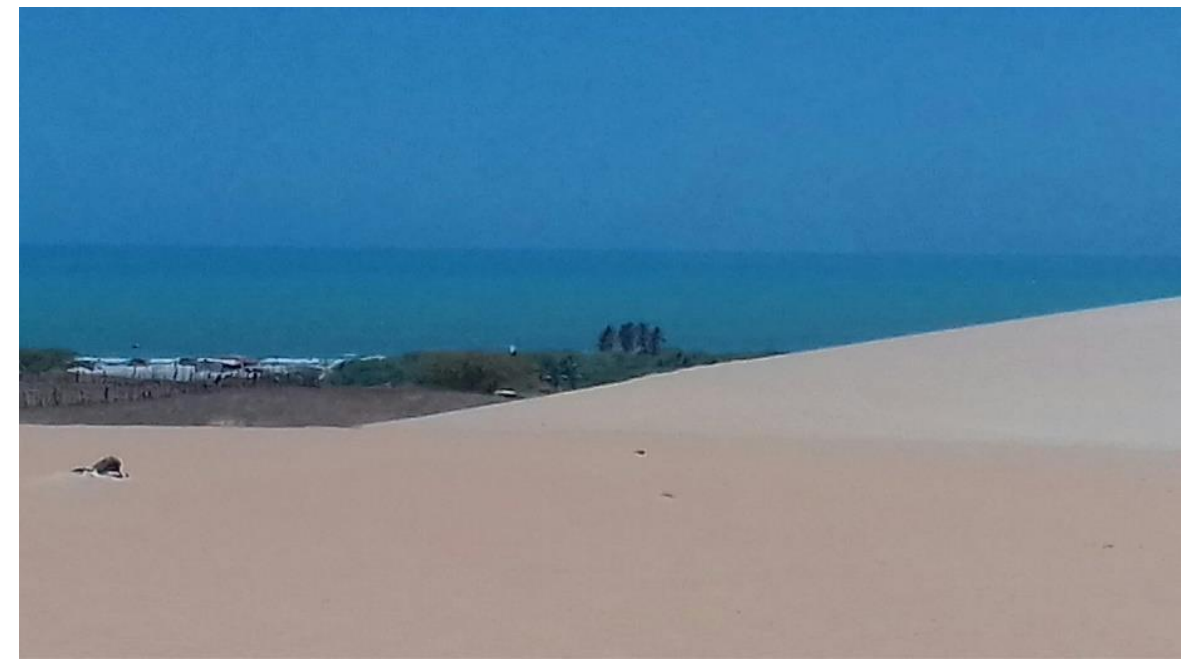

Figura 5 - Dunas do Rosado, Porto Mangue (RN), 2019.

Fonte: Arquivo do Projeto, 2019.

A APA na comunidade de São Cristóvão apresenta dois sítios paleontológicos pré-históricos em planície costeira, sendo um deles devidamente cadastrado no Instituto do Patrimônio Histórico e Artístico Nacional (IPHAN), Sítio Arqueológico Litorâneo Mel 2. Esse sítio apresenta materiais líticos e fragmentos cerâmicos, resquícios de antepassados vividos naquela comunidade. Martins et al. (2017) o descreve como um sítio arqueológico a céu aberto 
contendo vestígios líticos, cerâmicos, metálicos, vítreos, louças domésticas, olarias, além de vestígios orgânicos (conchostráceos e gastrópodes), tendo como ponto central de georeferenciamento do perímetro interno as coordenadas Datum SIRGAS 2000 UTM 24 M E 724565 e N 9453967 e com uma cota altimétrica média de 10 m, encontra-se situado a 16,769 km (na direção Oeste) da zona urbana do município de Areia Branca).

Assim, é possível perceber a necessidade de ações governamentais eficazes, no sentido de fiscalizar obras de grandes emprendimentos e até mesmo há uma ausência de políticas públicas voltadas para a efetivação da preservação do patromônio natural e paisagístico na região, com potencial de geração de renda para os moradores locais.

\subsection{Conflitos socioambientais em decorrência da instalação do parque eólico}

Constatou-se, a partir da análise realizada com os conteúdos das questões abertas dos questionários aplicados, que na comunidade há diferentes conflitos decorrentes da instalação do parque eólico, sendo classificados em cinco grupos de respostas, conforme a Tabela 1.

Tabela 1 - Conflitos por grupos na comunidade de São Cristóvão, Areia Branca (RN), 2018.

\begin{tabular}{c|c|c}
\hline Grupo & $\begin{array}{c}\mathbf{N}^{\circ} \text { de individuos } \\
\text { associados aos conflitos }\end{array}$ & $\begin{array}{c}\text { Representação } \\
\text { (\%) }\end{array}$ \\
\hline 01 & 09 & 12 \\
\hline 02 & 17 & 20 \\
\hline 03 & 36 & 46 \\
\hline 04 & 16 & 20 \\
\hline 05 & 02 & 02 \\
\hline Total & 80 & $100 \%$ \\
\hline
\end{tabular}

Fonte: Pesquisa de campo, 2018.

O Grupo 1 é formado pelos participantes que confirmam a existência de conflitos socioambientais na comunidade (12\%). Segundo esses participantes, os conflitos estão associados à instalação do empreendimento eólico. O conflito pela posse da terra é um dos mais relevantes. Este vem sendo motivado pela apropriação indevida de terras, por pessoas 
que não são residentes da comunidade. A população local e pessoas externas têm se apossado de terras, visando à valorização dessas áreas para a implantação de novos aerogeradores. Segundo os representantes do poder público municipal, "as terras são apropriadas ilegalmente pela ausência da regularização fundiária na área" (informação verbal) $)^{3}$.

O Grupo 2, que corresponde a $20 \%$ dos participantes, afirmou que o parque eólico está diretamente associado aos conflitos presentes na região, principalmente pela especulação energética realizada a partir de outras empresas, considerando o alto potencial para a geração de energia. Esse fato tem ocasionado uma expressiva especulação imobiliária, e, associado aos atrativos turísticos da região, tem alterado consideravelmente a paisagem local, promovendo uma "nova paisagem", a tecnologia dos aerogeradores. Este grupo de entrevistados destaca que o empreendimento tem causado conflitos internos, também pelo fechamento de uma estrada construída há mais de 100 anos, que era usada por pescadores no embarque e desembarque de barcos de pesca na comunidade.

Foi possivel identificar que os moradores sentem-se enganados pela empresa. Eles enfatizam, principalmente, que as compensações pela implantação do empreendimento na comunidade nunca foram realizadas, como é destacada pelo colaborador: "as promessas feitas pela empresa gestora do Parque Eólico Mel 2, no período de implantação, na reunião promovida na comunidade, nunca foram realizadas" (informação verbal) ${ }^{4}$. Os moradores reinvindicavam na época da instalação do empreendimento principalmente a pavimentação do acesso que liga a rodovia estadual RN 404 à comunidade de São Cristóvão, que havia sido uma promessa da empresa, durante reunião com a comunidade de São Cristóvão, bem como em audiência pública promovida pela Prefeitura Municipal de Areia Branca, todavia os registros da referida audiência não foram encontrados na Preifeitura de Areia Branca.

O Grupo 3 é o mais representativo (46\%) dos participantes da pesquisa. Os seus repsentantes afirmam que os conflitos pela terra na comunidade estão associados à grilagem de terras promovida por uma instituição particular de ensino, a Faculdade de Enfermagem e de Medicina Nova Esperança (FACENE), assim protocolado em juízo pela $1 \stackrel{\text { a }}{ }$ Vara do Trabalho de

\footnotetext{
${ }^{3}$ Entrevista concedida por G.J., representante do poder público municipal, aos pesquisadores.

${ }^{4}$ Entrevista concedida por G.H.S., representante do poder público, aos pesquisadores.
} 
Mossoró, processo 11-0595-94 (RT), presente na referida vara. Cabe ressaltar que a FACENE e o empreendimento eólico disputaram a posse de terras com parte dos comunitários. Segundo os entrevistados, os interesses da referida instituição estão voltados para a construção hoteleira na comunidade, bem como a promoção de estudos eólicos para a implantação futura de novos aerogeradores em São Cristóvão. De acordo com o Processo $\mathrm{n}^{\circ}$ 59500-67.1994.5.21.0011 (RT), expedido pela 1ạ Vara do Trabalho na Comarca de Mossoró, esse tipo de conflito está intrinsicamente vinculado à alienação de terras, assim chamada de grilagem de terras. O termo "Grilagem" teve origem em uma prática antiga de envelhecer documentos forjados para conseguir a posse determinada. Os papéis eram colocados em um caixote com "grilos" e, com o passar do tempo, a ação dos insetos dava aos documentos um aspecto antigo de uso (Silva, 2018).

Com base na decisão expedida no dia 20 de outubro de 2016 pela magistrada responsável pelo processo, que atuou pela primeira vez em 11 de novembro de 2014, realizando uma análise da denúncia de expulsão de pessoas das terras, utilizou-se de força armada (Processo № 59500-67.1994.5.21.0011 [RT] p. 3719). Durante esse fato, ficou constatada a preocupação da Prefeitura Municipal de Areia Branca para solucionar o problema, propondo, assim, uma audiência pública, na qual o presente processo foi discutido. Convidada a participar da audiência pública para tratar dessa questão de apropriação indevida de terras na comunidade de São Cristóvão, a juíza responsável pela comarca alegou temor relativo à sua segurança pessoal e não compareceu à audiência. Entretanto, foi feito o registro documental da audiência pública e uma cópia desse documento foi remetida à magistrada de forma digital, endereçada à sua vara de atuação.

De acordo com os documentos que foram consultados, o centro do conflito foi a denúncia que a FACENE estava usando de ameaças para expulsar moradores locais das terras das quais ela alega ser proprietária. Segundo os entrevistados, empregados dessa Faculdade atuam armados, ameaçando moradores e depreciando os barcos de pesca dos pescadores locais, que eles denominam de clima de "terrorismo" na comunidade.

Em síntese, conforme documentos pesquisados no Cartório de Areia Branca, esse conflito é resultante de um ato de penhora de terra, que, por sua vez, é representado por uma área total de 3.610 hectares (ha), situado no município de Areia Branca, compreendendo a face da junção de duas matrículas, sendo elas: matrícula de no 259, do livro 2-A (Fazenda Hiaskara) e 
no 1.125, do livro 2-D (Fazenda Modelo). As terras foram adquiridas face a um leilão, consequência dos bens penhorados da então empresa Dunas Agroindustrial S/A, em virtude de um processo trabalhista. Contudo, os bens legais referentes à área de 3.610 ha, por meio de vistorias realizadas durante o processo, demonstraram uma alienação de 2.839,0957 ha (Processo № 59500-67.1994.5.21.0011 [RT]. p. 3731). Sendo assim, a área requisitada de 3.610 ha, pertencente à FACENE, por meio de leilão realizado pelo Banco do Nordeste, não se encontra nos limites da comunidade de São Cristóvão, cabendo à instituição a adaptação aos limites reais da área penhorada.

A alienação ou grilagem de terras não configura novidade na comunidade e no Brasil. Nos últimos anos, essa disputa envolve principalmente famílias camponesas e populações tradicionais. $\mathrm{O}$ aumento de casos de grilagem deu-se principalmente em função do aumento da transação de investidores, governos ou multinacionais que têm se apropriado de grandes áreas de terra. Na maioria das vezes, esse tipo de conflito envolve despejos e ataques armados, amedrontando a população residente na luta por seus direitos (Silva, 2018).

Por fim, os Grupos 4 e 5, que juntos correspondem a 22\% dos participantes, afirmaram não existir nenhum tipo de conflito na comunidade ou não souberam responder. Os representantes do Grupo 4 (20\%) demostraram cuidado com o emprego das palavras e apresentavam receio de discutir os conflitos comunitários a partir da instalação do parque eólico e, sobretudo, da disputa de terras entre a FACENE, o empreendimento eólico e a comunidade. Já o Grupo 5 (2\%) foi composto pelos participantes que disseram não saber reponder a essa questão.

Parte significativa dos participantes da pesquisa relatou que, durante esses conflitos, já chegou a ocorrer disparos de tiros para o alto, quando os moradores demostraram resistência à desocupação das terras. Muitos moradores admitem sentir receio de se expor, uma vez que essa disputa permanece ainda muito presente na comunidade.

Com o intuito de entender o comportamento dos cinco grupos estudados, diante dos conflitos estabelecidos na comunidade de São Cristóvão, utilizando-se do coeficiente de correlação nas unidades, foram estabelecidas relações sobre o número de indivíduos associados aos conflitos, a média de idade, a escolaridade e o sexo dos entrevistados, conforme atesta o Quadro 2. 
Quadro 2 - Visão das unidades de correlações analisadas na comunidade de São Cristóvão, Areia Branca (RN), 2018.

\begin{tabular}{|c|c|c|c|}
\hline Grupos/Conflitos & $\begin{array}{l}\text { Média de } \\
\text { Idades }\end{array}$ & $\begin{array}{c}\text { Nivel Escolaridade dos } \\
\text { Entrevistados }\end{array}$ & Sexo \\
\hline $\begin{array}{l}\text { Grupo } 1-\text { conflito } \\
\text { associado } \\
\text { empreendimento eólico } \\
\text { (apropriação indevida } \\
\text { de terras na } \\
\text { comunidade após a } \\
\text { implantação do parque } \\
\text { eólico). }\end{array}$ & 46 anos & $\begin{array}{l}\text { Ens. médio completo (1) } \\
\text { Ens. médio Incompleto ( } 2 \text { ) } \\
\text { Ens. fundamental Incompleto (6) }\end{array}$ & $\begin{array}{l}M^{*}(3) \\
F^{*}(6)\end{array}$ \\
\hline $\begin{array}{lr}\text { Grupo } 2- & \text { conflito } \\
\text { motivado diretamente } \\
\text { por empresas do ramo } \\
\text { energético r } \\
\text { imobiliário. }\end{array}$ & 45 anos & $\begin{array}{l}\text { Ensino médio completo (6) } \\
\text { Ensino médio Incompleto (3) } \\
\text { Ens. fundamental Incompleto (6) } \\
\text { Ens. fundamental Completo (1) } \\
\text { Não Alfabetizado (1) }\end{array}$ & $\begin{array}{l}M(8) \\
F(8)\end{array}$ \\
\hline $\begin{array}{l}\text { Grupo } 3 \text { - conflito na } \\
\text { comunidade associado } \\
\text { ao empreendimento } \\
\text { eólico (grilagem de } \\
\text { terras promovida por } \\
\text { uma empresa de ensino } \\
\text { particular). }\end{array}$ & 46 anos & $\begin{array}{l}\text { Ensino médio completo (6) } \\
\text { Ensino méd. Incompleto (3) } \\
\text { Ensino fund. Incompleto (6) } \\
\text { Ensino fund. Completo (1) } \\
\text { Não Alfabetizado (1) }\end{array}$ & $\begin{array}{l}M(18) \\
F(19)\end{array}$ \\
\hline $\begin{array}{l}\text { Grupo } 4 \text { - não existem } \\
\text { conflitos. }\end{array}$ & 42 anos & $\begin{array}{l}\text { Ensino médio completo (5) } \\
\text { Ensino médio incompleto (1) } \\
\text { Ens. fundamental incompleto (5) } \\
\text { Ensino superior incompleto (1) } \\
\text { Não afalbetizado (4) }\end{array}$ & $\begin{array}{l}M(5) \\
F(11)\end{array}$ \\
\hline $\begin{array}{l}\text { Grupo } 5 \text { - não soube } \\
\text { responder se há } \\
\text { conflitos. }\end{array}$ & 39 anos & Ens. fundamental incompleto (2) & $F(2)$ \\
\hline
\end{tabular}

Fonte: Pesquisa de Campo, 2017/2018.

Ao observar a visão geral das unidades analisadas, foi possível investigar as relações entre as variáveis (grupos de conflitos, representados pelo número de indivíduos de cada grupo, média de idade dos entrevistados, nível de escolaridade e sexo). Essa relação foi representada pela variável independente (número de indivíduos de cada grupo) e as variáveis dependentes (média de idade, escolaridade e sexo).

De acordo com a Figura 6, é possivel observar que o número de indivíduos associados a conflitos possui uma baixa relação, com a variável idade $\left(R^{2} 0,5218\right)$. Pesquisa realizada por 
Oliveira, Cavazotte e Paciello (2013), ao comparar variáveis com a idade dos participantes, também verificou pouca relação com grupo associado a conflito, o que indica que a idade apresenta pouca relação com as variáveis relacionadas a conflitos.

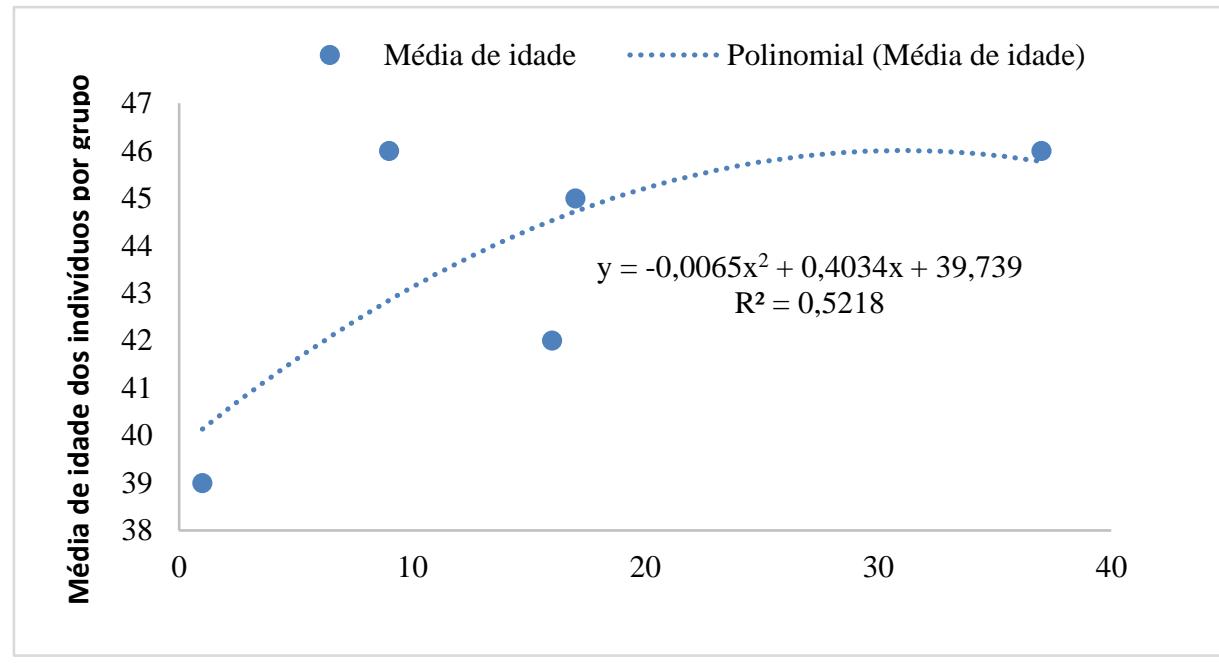

Número de indivíduos por grupo

Figura 6 - Gráfico da Correlação entre número de indivíduos dos grupos de conflitos e idade, 2018.

Fonte: Pesquisa de Campo, 2017/2018.

Na Figura 7, é possível observar que há uma alta correlação entre as variáveis estudadas (grupos de conflito e sexo). Além disso, a variável dependente (sexo) foi influenciada pela variável independente (grupos de conflito). 


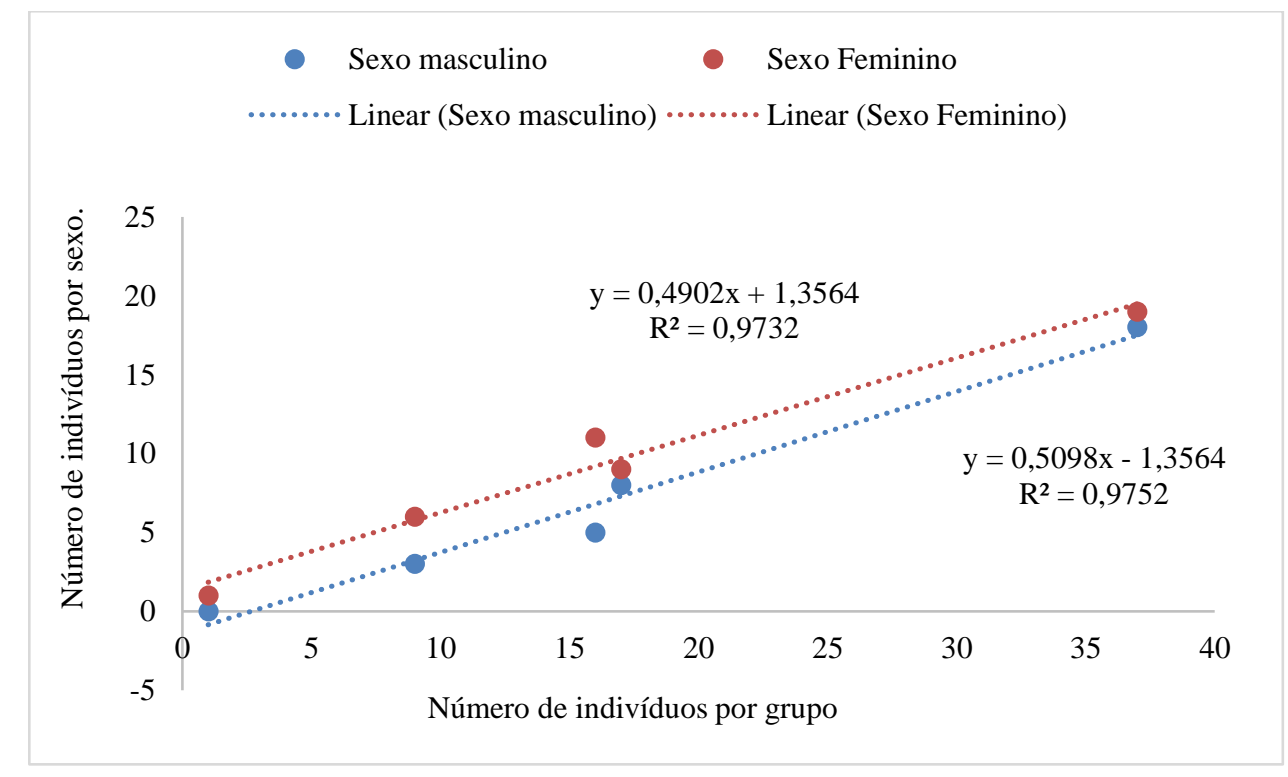

Figura 7 - Gráfico da Correlação entre o número de indivíduos por sexo e por grupos.

Fonte: Pesquisa de Campo, 2017/2018.

Em sua pesquisa, Silva (2018) cita que a questão do gênero está relacionada a conflitos principalmente pela importância cultural que as populações empregam ao local. Geralmente, está diretamente ligada ao recebimento da propriedade por parte de herança dos pais. A construção da identidade e o sentimento de pertencimento são observados na defesa dos seus territórios de reprodução social, econômica e cultural. A grande representatividade feminina mobiliza a maioria dos conflitos na comunidade. As mulheres estão na luta e resistência à defesa do território.

Já a correlação entre o número de indivíduos e o nível de escolaridade variou dentro dos três níveis: baixa, média e alta correlação. A seleção do Grupo 1 (ensino médio completo, ensino médio incompleto, ensino fundamental completo) associado ao Grupo 2 (ensino médio completo, ensino médio incompleto, ensino fundamental completo, ensino fundamental incompleto, ensino superior incompleto e não alfabetizado) apresenta uma alta correlação entre as variáveis analisadas (grupos de conflitos e escolaridade), em que as variáveis dependentes (escolaridade) foram influenciadas pela variável independente (grupos de conflitos). Já a correlação entre o Grupo 1 e o Grupo 3 (ensino médio completo, ensino médio incompleto, ensino fundamental completo, ensino fundamental incompleto e sem instrução) 
apresenta média correlação entre os grupos de conflitos, uma vez que o valor de $\mathrm{R}^{2}$ foi de 0,5741 .

A correlação entre os Grupos 1 e 4 (ensino médio completo, ensino médio incompleto, ensino fundamental completo, ensino fundamental incompleto, ensino superior incompleto e não alfabetizado), correspondem a uma correlação baixa, não significativa, onde $\mathrm{R}^{2}$ corresponde a 0,4384. Também a correlação entre o grupo 1 e o grupo 5 (ensino fundamental incompleto) apresenta baixa correlação, o que representa o valor de $R^{2}$ de 0,1375.

Cabe destacar que a formação educacional pode ser um grande facilitador na existência de conflitos, já que o ambiente escolar motiva a crítica e a discussão de temas contemporâneos ou antepassados. Portanto, a pluralidade cultural, empregada pela distribuição de terras de herança dos pais, cria um forte vínculo dentro da comunidade.

Logo, não há uma sociedade sem conflitos, já que surgem naturalmente, conforme as diferenças de cada indivíduo, como desejos, valores e necessidades. Porém, não se pode confundir a luta e a defesa pelos espaços de (re)produção social e econômica, com a violência. O diálogo e a articulação dos grupos pode fortalecer a luta e a defesa do seu espaço cultural, visando a união da sociedade para a resolução de conflitos.

\section{Considerações finais}

A ausência de diálogo por parte das empresas do ramo energético e instituições governamentais, sejam elas federais, estaduais ou municipais, para com as populações adjacentes aos empreendimentos eólicos traz como consequência conflitos. Estes, por sua vez, são decorrentes principalmente de promessas inventadas pelos empreendimentos, as quais nem sempre são atendidas.

Nessa perspectiva, foi possível identificar a insatisfação por parte da comunidade sobre a instalação do parque eólico, evidenciando a pouca contribuição para a economia local, aos conflitos latifundiários (especulação imobiliária e energética) associados ao parque eólico e à instalação dos aerogeradores dentro da APA Dunas do Rosado.

Com relação aos conflitos estabelecidos na comunidade, fica evidente a existência de três grupos de conflitos. O primeiro formado indiretamente pelo empreendimento eólico 
(apropriação indevida de terras após a implantação do parque); o segundo motivado diretamente por empresas do ramo energético e imobiliário, este último decorrente de promessas não concretizadas, e o terceiro ligado indiretamente ao empreendimento eólico, caracterizado principalmente por grilagem de terras na região. Em todos esses grupos, os conflitos apresentam relação com a instalação do parque eólico, o que caracteriza questões de interesses individuais em detrimento dos interesses coletivos.

A respeito das correlações apresentadas, fica claro que os conflitos estão diretamente correlacionados à questão do gênero, através do vínculo cultural a um dado espaço, sendo, na maioria das vezes, propriedades adquiridas por meio de herança dos pais. Outra variável a ser considerada é o nível de escolaridade, uma vez que, por meio da educação, os sujeitos adquirem conhecimentos e formam um pensamento crítico, capaz de questionar e promover debates em relação à sua condição de vida, direitos e deveres enquanto cidadãos.

A partir desta investigação, é possivel afirmar que a introdução dos parques eólicos no Brasil vem sendo viabilizada por meio de políticas públicas que visam à ampliação de fontes de produção energética renováveis, que a partir da última década expandiram-se em todo o país, particularmente nos estados da Região Nordeste. Todavia, no contexto da implantação desse modelo de desenvolvimento territorial, torna-se uma preocupação a preservação do meio ambiente e de grupos culturais que, por vezes, esperam que a dinamização da economia por meio de investidores externos ocasione um impulso no quadro de emprego local e absorção da mão de obra comunitária, aspectos que não foram observados em São Cristóvão.

\section{Agradecimentos}

Ao CNPq, pelo financiamento do projeto Impactos da Energia Eólica no Litoral do Nordeste: perspectivas para a construção de uma visão integrada da produção de energia "limpa" no Brasil, edital CNPq - Bolsas no País Modalidade Pesquisador Visitante Especial no 09/201, processo 88881.068108/2014-01. Ao CNPq, por meio do projeto Políticas Territoriais, Governança Ambiental e Energias Renováveis: a Implementação do Parque Eólica na Comunidade de São Cristóvão, Areia Branca (RN). Edital n 003/2016-DPI/PROPEG/UERN (PIBIC/CNPq 2017/2018). 


\section{REFERÊNCIAS BIBLIOGRÁFICAS}

BARBOSA FILHO, W. P. Impactos ambientais em usinas eólicas. AGRENER GD 2013. p. 17. Itajubá - MG, 2013. Disponível em: http://www.feam.br/images/stories/arquivos/mudnacaclimatica/2013/ag-267.pdf. Acesso em: 20 abr. 2018.

BRASIL. AGÊNCIA NACIONAL DE ENERGIA ELÉTRICA - ANEEL. Processo 48500.000676/2012-31. Disponível em: http://www2.aneel.gov.br/aplicacoes/noticias/Output_Noticias.cfm?ldentidade=5334\&id_area=90. Acesso em: 15 mar. 2017.

BRASIL. Resolução CONAMA № 462, de 24 julho de 2014. Estabelece procedimentos para o licenciamento ambiental de empreendimentos de geração de energia elétrica a partir de fonte eólica em superfície terrestre, altera o art. 1ㅇ da Resolução CONAMA n. 279, de 27 de julho de 2001, e dá outras providências.Brasília: Ministério do Meio Ambiente, 2014.

BRASIL. Resolução $\mathrm{n}^{\circ} 462$ CONAMA. Estabelece procedimentos para o licenciamento ambiental de empreendimentos de geração de energia elétrica a partir de fonte eólica em superfície terrestre e dá outras providências. Diário Oficial da República Federativa do Brasil, Brasília, 24 jul. 2014, Sec. 1, p. 96. Disponível em: http://www2.mma.gov.br/port/conama/legiabre.cfm?codlegi=703. Acesso em: 09 dez. 2020.

BRASIL. Contribuição da atividade de projeto do parque eólico Mel 2 para o Desenvolvimento Sustentável. Brasília: Ministério da Ciência, Tecnologia, Inovações e Comunicações - MCTIC, 2012. Disponível em: https://www.mctic.gov.br/mctic/export/sites/institucional/ciencia/SEPED/clima/mecanismo_de_desenvolvim ento_limpo/submetidos/aprovados_termos_resolucao_1/publicacoes/333/Anexo-III-da-Resolucao-n.-1.pdf. Acesso em: 15 mar. 2018.

BRASIL. AGÊNCIA NACIONAL DE ENERGIA ELÉTRICA - ANEEL. Atlas de energia elétrica do Brasil. Brasília: ANEEL, 2002. Disponível em: http://www2.aneel.gov.br/arquivos/pdf/atlas3ed.pdf. Acesso em: 10 ago. 2020.

BRASIL. Lei № 10.438, de 26 de abril de 2002. Dispõe sobre a expansão da oferta de energia elétrica emergencial, recomposição tarifária extraordinária, cria o Programa de Incentivo às Fontes Alternativas de Energia Elétrica (PROINFA), a Conta de Desenvolvimento Energético (CDE), dispõe sobre a universalização do serviço público de energia elétrica, dá nova redação às Leis no 9.427, de 26 de dezembro de 1996, no 9.648, de 27 de maio de 1998, no 3.890-A, de 25 de abril de 1961, no 5.655, de 20 de maio de 1971, no 5.899, de 5 de julho de 1973, n- 9.991, de 24 de julho de 2000, e dá outras providências. Brasília: Ministério das Minas e Energia, 2002. Disponível em: http://www.planalto.gov.br/ccivil_03/leis/2002/L10438.htm. Acesso em: 21 dez. 2020.

BRASIL. Lei № 9.478, de 6 de agosto de 1997. Dispõe sobre a política energética nacional, as atividades relativas ao monopólio do petróleo, institui o Conselho nacional de Política Energética e a Agência Nacional do Petróleo e dá outras providências. Brasília: Ministério de Minas e Energia, 1997. Disponível em: http://www.planalto.gov.br/ccivil_03/leis/19478.htm. Acesso em: 21 abr. 2018.

BRASIL. Resolução CONAMA no 001, de 23 de janeiro de 1986. Brasília: Conselho Nacional do Meio Ambiente IBAMA, $1986 . \quad$ Disponível em: http://www.cprh.pe.gov.br/ARQUIVOS ANEXO/resolu\%C3\%A7\%C3\%A30\%20conama\%200186;1505;20100818 .pdf. Acesso em: 17 jan. 2021.

BRASIL. Lei № 6.938, de 31 de agosto de 1981. Dispõe sobre a Política do Meio Ambiente, seus fins e mecanismos de formulação e aplicação, e dá outras providências. Disponível em: < http://www.oas.org/dsd/fida/laws/legislation/brazil/brazil_6938.pdf>. Acesso em: 21 abr., 2020.

CAVALCANTE, H. P. M. O acesso à energia elétrica no Brasil sob a ótica do desenvolvimento como liberdade. Direito Econômico e Socioambiental, Curitiba, v. 4, n. 2., p. 58-86, 2013. doi: 10.7213/rev.dir.econ.socioambienta.04.002.A004. Disponível em: https://periodicos.pucpr.br/index.php/direitoeconomico/article/view/6146. Acesso em: 10 mai. 2018.

CUNHA, O.; SILVA, M. R. F.; CARVALHO, R. G. Os novos ventos: a (re) produção territorial a partir da introdução de parques eólicos no Rio Grande do Norte. Braz. J. of Develop., Curitiba, v. 5, n. 10, p. 21944-21957, out. 2019. DOI:10.34117/bjdv5n10-331. Disponível em: file://C:/Users/mregi/Downloads/4152-11339-1-PB.pdf. Acesso: 06 jan. 2021. 
FONSECA, J. J. S. Metodologia da pesquisa científica. Fortaleza: UEC, 2002.

GÊ, D. R. R.; CARVALHO, R. G.; SILVA, M. R, F. Unidades de Conservação e energia eólica no Rio Grande do Norte: o caso da Reserva de Desenvolvimento Sustentável Ponta do Tubarão. In: GORAYEB, A.; BRANNSTROM, C.; MEIRELES, A. J. A. Impactos socioambientais da implantação dos parques de energia eólica no Brasil. Fortaleza: Edições UFC, 2019.

IBGE. INSTITUTO BRASILEIRO DE GEOGRAFIA E ESTATÍ́STICA. Areia Branca. Rio de Janeiro: IBGE, 2021. Disponível em: https://cidades.ibge.gov.br/brasil/rn/areia-branca/panorama. Acesso em: 07 jan. 2021.

IBGE. INSTITUTO BRASILEIRO DE GEOGRAFIA e eSTAtístICA. Perfil minha cidade. Rio de janeiro: IBGE, 2015. Disponível em: https://cidades.ibge.gov.br/brasil/rn/areia-branca/panorama. Acesso em: 05 mar. 2015.

MARTINS, A. J. D. A; GUIMARÃES, R; GURGEL, S. P; SANTOS JUNIOR, V. A influência da dinâmica costeira em sítios arqueológicos dunares: Estudo de caso na praia de Redonda, município de Areia Branca, RN. Clio Arqueologia. Recife: Universidade Federal do Pernambuco, 2017.

MEDEIROS, W; CUNHA, L; ALMEIDA, A. C. de. Riscos ambientais no litoral: estudo comparativo Brasil-Portugal. Cadernos de Geografia Coimbra, FLUC, Coimbra, p. 107-115, 2011. DOI:http://dx.doi.org/10.14195/08711623_31_10. Disponível em: <https://digitalis-dsp.uc.pt/bitstream/10316.2/30208/1/CG3031_artigo11.pdf>.Acesso em: 18 jan. 2021.

MEIRELES, A. J. A. Danos socioambientais originados pelas usinas eólicas nos campos de dunas do nordeste brasileiro e critérios para definição de alternativas locacionais. Confins, v. 11, p. 1-20. 2011. https://doi.org/10.4000/confins.6970. Disponível em: https://journals.openedition.org/confins/6970?lang=pt. Acesso em: 18 mai. 2020.

MEIRELES, A. J. A. et al. Impactos da Energia Eólica no Litoral do Nordeste: perspectivas para a construção de uma visão integrada da produção de energia "limpa" no Brasil. Projeto de Pesquisa. Edital CNPq - - Bolsas No País Modalidade Pesquisador Visitante Especial - PVE da Chamada de Projetos MEC/MCTI/CAPES/CNPQ/FAPS no 09/201, Processo 88881.068108/2014-01. Fortaleza: Universidade Federal do Ceará/Universidade do Texas - EUA, 2014.

MOREIRA, T. R.; SANTOS, A. R.; DALFI, R. L.; CAMPOS, R. F.; SANTOS, G. M. A. D. A.; EUGENIO, F. C. Confronto do Uso e Ocupação da Terra em APPs no Município de Muqui, ES. Floresta e Ambiente. Vitória - ES: v. 22, n.2, pp. 141-152, 2015. https://doi.org/10.1590/2179-8087.019012. Disponível em: http://www.scielo.br/scielo.php?script=sci_arttext\&pid=S2179-80872015000200141\&lng=pt\&tlng=pt. Acesso em: 16 mai. 2018.

MORELLI, F. S. Panorama geral da energia eólica no Brasil. 2012. 77f. Monografia (Graduação em Engenharia) Universidade de São Paulo - USP, São Carlos - SP. Disponível em: http://www.tcc.sc.usp.br/tce/disponiveis/18/180500/tce-04022013-

101829/publico/Morelli_Francis_de_Souza.pdf. Acesso em: 23 mar. 2018.

NASCIMENTO, T. C.; MENDONÇA, A. T. B.; CUNHA, S. K. Inovação e sustentabilidade na produção de energia: o caso do sistema setorial de energia eólica no Brasil. Cadernos EBAPE.BR, v. 10, n. 3, p. 630-651, 2012. $\quad$ https://doi.org/10.1590/S1679-39512012000300010. Disponível em: https://www.scielo.br/scielo.php?script=sci abstract\&pid=S167939512012000300010\&lng=en\&nrm=iso\&tlng=pt. Aceso em: 15 jan. 2021.

OLIVEIRA, L. B.; CAVAZOTTE, F. S. C. N.; PACIELLO R. R. Antecedentes e consequências dos conflitos entre trabalho e família. Revista de Administração Contemporânea, Rio de Janeiro, v. 17, n. 4. p. 418-437, 2013. Disponível em: http://www.scielo.br/pdf/rac/v17n4/a03v17n4.pdf. Acesso em: 12 jun. 2018.

ONU. ORGANIZAÇÃO DAS NAÇÕES UNIDAS. Cúpula das Nações Unidas Sobre o Desenvolvimento Sustentável. Nova Yorque: ONU, 2000. Disponível em https://nacoesunidas.org/pos2015/agenda2030/. Acesso em: 31 mai. 2018.

ONU. ORGANIZAÇÃO DAS NAÇÕES UNIDAS. Objetivos de desenvolvimento sustentável. ONU: Agenda 2030, s.d. Disponível em: http://www.agenda2030.org.br/ods/7/. Acesso em: 06 jan. 2021. 
SILVA, I. H. M. Moinhos de ventos: a energia eólica na comunidade de São Cristóvão, município de Areia Branca (RN). 2018. 89f. Monografia (Graduação em Gestão Ambiental) - Universidade do Estado do Rio Grande do Norte, Faculdade de Ciências econômicas, Mossoró.

SILVA, M. R. F da. Políticas Territoriais, Governança Ambiental e Energias Renováveis: a Implementação do Parque Eólico na Comunidade de São Cristóvão, Areia Branca (RN). Projeto de Pesquisa. Edital n 003/2016DPI/PROPEG/UERN (PIBIC/CNPq 2017/2018), Mossoró: Diretoria de Pesquisa e Inovação/Departamento de Institucionalização da Pesquisa/UERN, 2017.

TAVARES, G. J. S. Uso do território na microrregião da Serra de Santana a partir da instalação de parques eólicos. 2016. 108f. Dissertação (Mestrado em Geografia) - Universidade Federal do Rio Grande do Norte, Centro de Ciências Humanas, Letras e Artes, Programa de Pós-Graduação e Pesquisa em Geografia, Natal. Disponível em:

https://repositorio.ufrn.br/jspui/bitstream/123456789/21305/1/GeraldaJulietTavaresDeSouza_DISSERT.pdf. Acesso em: 03 dez. 2020.

VEIGA, J. E.; OLIVEIRA, A.; PEREIRA, O. Energia eólica. 1. ed. São Paulo: Senac, 2012. 213p.

XAVIER, Y. M. A.; ALVES, F. G.; GUIMARÃES, P. B. V. Direito das energias renováveis e desenvolvimento. Natal: UDUFRN, 2013. 